\title{
FUNDAMENTOS METODOLÓGICOS DO IMAGINÁRIO: MITOCRÍTICA E MITANÁLISE
}

\section{METHODOLOGICAL FOUNDATIONS OF THE IMAGINARY: MYTH- CRITICISM AND MYTH-ANALYSIS}

\author{
Alberto Filipe Araújo ${ }^{1}$ \\ Rogério de Almeida ${ }^{2}$
}

\begin{abstract}
Resumo
Os objetivos deste artigo são os de estudar os fundamentos metodológicos da Antropologia do Imaginário, com destaque à mitocrítica e à mitanálise, duas heurísticas capitais para o tratamento mitológico - ou mitodológico - de textos, respectivamente os literários, e os da própria sociedade, compreendidos em sua redundância simbólica; e o de destacar as pesquisas contemporâneas que têm se debruçado sobre os mitos atualmente em circulação nas sociedades ocidentais, para a compreensão da metodologia em questão e sua contribuição para os modos de interpretação do tempo presente.
\end{abstract}

Palavras-chave: Antropologia do Imaginário. Mitocrítica. Mitanálise. Mitos contemporâneos.

\begin{abstract}
The objectives of this article are on the one hand, to study the methodological foundations of Imagery Anthropology, with emphasis on myth criticism and myth analysis, two capital heuristics for the mythological - or "mythodological" - treatment of texts, respectively the literary ones, and the societal ones, as far as their symbolic redundancy is concerned; on the other hand, to highlight contemporary research that has been focusing on the myths currently circulating in Western societies so that one understands the methodology in question and its contribution to the modes of interpretation of present time.
\end{abstract}

Keywords: Anthropology of Imagery. Myth criticism. Myth analysis. Contemporary Myths.

\footnotetext{
${ }^{1}$ Professor Catedrático do Departamento de Teoria da Educação e Educação Artística e Física do Instituto de Educação da Universidade do Minho (Braga-Portugal). É membro integrado do Centro de Investigação em Educação (CIEd) do Instituto de Educação da Universidade do Minho (Braga - Portugal). "Este trabalho é financiado pelo CIEd - Centro de Investigação em Educação, projetos UID/CED/1661/2013 e UID/CED/1661/2016, Instituto de Educação, Universidade do Minho, através de fundos nacionais da FCT/MCTES-PT.”

${ }^{2}$ Professor Associado do Departamento de Administração Escolar e Economia da Educação da Faculdade de Educação da Universidade de São Paulo.
} 
Fundamentos metodológicos do imaginário: mitocrítica e mitanálise

Os últimos passos da mitocrítica caminham progressivamente para uma mitanálise e mesmo para uma filosofia - totalmente empírica da história e da cultura.

Gilbert Durand (Champs de l'Imaginaire, p. 242)

\section{Introdução}

Gilbert Durand $\left(1979^{a}, 1979^{b}\right)$ defende que há continuidade entre as antigas mitologias e as narrativas modernas como literatura, cinema, filosofia, política, história etc. Ainda que o mito não seja nomeado ou apareça diretamente nessas narrativas, ele está lá presente, em um nível simbólico, sustentando o sentido desses textos, discursos e imagens. O trabalho do hermeneuta é justamente trazer à tona dessas formulações seu(s) mito(s) subjacente(s). Para essa tarefa de penetrar no imaginário e compreender os mitos que o configuram, Gilbert Durand $\left(1979^{\mathrm{a}}, 1979^{\mathrm{b}}, 1994,1996,2000\right)$ desenvolve duas heurísticas, dois recursos metodológicos - ou mitodológicos, se se preferir -, a saber: a mitocrítica e a mitanálise. O imaginário muitas vezes aparece conotado negativamente, sendo associado a dimensões fantasistas, lúdicas, oníricas e poéticas, enquanto as noções de símbolo ou de utopia normalmente são encaradas mais positivamente na ordem da construção social. Por outro lado, constata-se uma ressurgência, talvez até inesperada, da noção de imaginário através, por exemplo, da valorização dos contos e das pequenas narrativas (as chamadas storytelling) na vida social e política contemporânea, assim como o imaginário não deixa de estar igualmente presente no desenvolvimento das tecnologias da comunicação, das biotecnologias que parecem reativar os mitos de Frankenstein e Drácula, da "Juventude eterna" e mesmo toda a parafernália ligada à mitologia do Cyborg. Neste contexto interessa, desde já, referir que não consideramos o imaginário como um mero conjunto de representações fictícias, falsas ou ilusórias, ainda que admitamos que o imaginário, individual ou coletivo, não seja de todo a elas imune e que, por conseguinte, nesse sentido nos merece obviamente reservas e como tal deve ser rejeitado. Contudo, o imaginário é mais do que isso, ele é também - sublinhamos - uma linguagem simbólica universal através do qual conferimos forma às nossas emoções, às nossas imagens, às nossas ideias. O imaginário neste sentido é um tecido complexo de afetos e de representações que permite, por sua vez, exprimir significações e produção de sentido correndo mesmo o risco de ser objeto igualmente de erros e de ilusões à semelhança, aliás, da razão, como lembra um dos gravados 
Fundamentos metodológicos do imaginário: mitocrítica e mitanálise

de Goya, que pertence à série dos seus “Caprichos" (nº 43 datado de 1799), "El sueño de la razón produce monstruos" ("O sonho da razão produz monstros").

Constata-se, tendo as imagens como tela de fundo que constitui o imaginário, compreendido então como uma espécie de grande "bacia semântica", que na prática hermenêutica da mitocrítica os mitos nos textos literários não se adaptam à especificidade de textos fortemente ideologizados e pobres em espessura mítica, como são os textos educacionais e pedagógicos, tão só para citar aqueles que naturalmente nos são mais familiares. Também não sendo nós sociólogos nem historiadores ${ }^{3}$, a mitanálise não representa tampouco uma contribuição particular, ou específica, na captação dos fluxos míticos que circulam, em maior ou menor grau, no interior dos textos educacionais saturados ideologicamente. Face às limitações por nós experienciadas no trabalho hermenêutico dos textos educacionais e pedagógicos na busca da "presa" mítica, mesmo com o apoio da mitocrítica e da mitanálise, avançamos no nosso ponto sobre a mitanálise com a proposta da noção de ideologema, por nós revisitada, dado que ela nos permite trabalhar mais especificamente os textos educacionais e pedagógicos que são aqueles que de um modo muito especial nos ocupam.

Trataremos neste artigo inicialmente da mitocrítica, com a exposição de seus fundamentos e de seu modus operandi em busca de contextualizá-la no interior das contribuições aos estudos do imaginário realizadas por Gilbert Durand; na sequência, damos atenção especificamente à mitanálise, procedendo de modo semelhante ao tratamento dado à mitocrítica. Em seguida, apontaremos estudos contemporâneos que, por meio da mitodologia do imaginário, têm contribuído para a compreensão dos mitos que circulam na atualidade, com o duplo objetivo de pôr em perspectiva os modos de interpretação dos dias que correm e munir o hermeneuta de heurísticas que o guiem em suas prospecções pela Antropologia do Imaginário. A modos de conclusão, interrogar-nos-emos sobre a mais-valia, e eventuais limitações, da hermenêutica metodológica durandiana, além de resumirmos os principais aspectos tratados ao longo do nosso estudo.

\section{Da mitodologia durandiana}

\footnotetext{
${ }^{3}$ A nossa formação é filosófica, mais particularmente na área de especialidade em Filosofia da Educação. A nossa análise encontra-se fortemente influenciada pela teoria hermenêutica de Paul Ricoeur e pela hermenêutica simbólica do Círculo de Eranos (Ascona - Suíça).
} 
Fundamentos metodológicos do imaginário: mitocrítica e mitanálise

A mitocrítica é uma técnica de investigação que parte das obras literárias, artísticas, dos relatos, histórias de vida, documentos e narrativas de modo geral para depreender os mitos diretores dessas produções. Já a mitanálise busca delimitar os mitos diretores dos momentos históricos e dos grupos sociais. De modo sintético, a mitocrítica estuda o mito de uma obra enquanto a mitanálise se dedica ao mito de uma sociedade recortada no tempo e no espaço. Os últimos passos da mitocrítica, no entender de Gilbert Durand (1996, p. 229242), caminham progressivamente para uma mitanálise e podem inclusive conduzir a uma filosofia da história e da cultura. Desse modo, a mitanálise pode ser compreendida como uma extensão da mitocrítica: não se centra na obra, mas na sociedade, na época em que o(s) autor(es) se insere(m). Assim, podemos proceder a uma mitanálise partindo da análise de textos e formas literárias ou, em um caminho filosófico, partir das sequências e dos mitemas de um mito bem estabelecido, e ver como ressoa em uma dada sociedade de um determinado momento histórico (DURAND, 2000, p. 83-162, 187-209).

Enquanto a mitocrítica, domínio preferencial do literário, se debruça sobre o mítico, quer ele esteja patente ou latente, nas suas mais variadas facetas (mitemas, mitologemas etc.) no interior dos textos literários e poéticos, a mitanálise interessa mais particularmente ao sociólogo e ao historiador porquanto o mítico identificado é passível não só de uma análise hermenêutica (o domínio da mitocrítica), mas também de uma análise sócio-histórica (domínio específico da mitanálise). Já a mitanálise, assim, prolonga as orientações metodológicas da mitocrítica naquilo que diz respeito às práticas sociais, às instituições, aos documentos históricos, mesmo ao patrimônio artístico e arquitetônico. Ambas, mitocrítica e mitanálise, ao se debruçarem sobre a intertextualidade e a contextualidade, perfazem o que Durand chamou de mitodologia.

\subsection{Mitocrítica}

Gilbert Durand elabora o conceito de mitocrítica (1970) a partir da psicocrítica de Charles Mauron, particularmente da sua obra intitulada Des métaphores obsédantes au mythe personnel. Introduction à la psychocritique [Das metáforas obsessivas ao mito pessoal. Introdução à psicocrítica] (1949). Mais precisamente ele afirma que

O termo 'mitocrítica' foi forjado no ano de 1970 sobre o modelo daquele utilizado vinte anos mais cedo por Charles Mauron, a 'psicocrítica' (1949), para significar o emprego de um método de crítica literária ou artística que focaliza o processo compreensivo sobre a narrativa mítica inerente, como 
Fundamentos metodológicos do imaginário: mitocrítica e mitanálise

Wesenschau, à significação de toda a narrativa. (...) A mitocrítica pretende-se um método da crítica que seja a síntese construtiva entre as diversas críticas literárias e artísticas antigas e novas que até aqui se afrontavam esterilmente (DURAND, 1979a, p. 307-308, p. 168-169).

Antes já o autor tinha afirmado:

É a partir das reflexões sobre o primado do mito que se deduziu um método de análise do 'texto' mítico (narração, representação ritual, icónica, etc.) de que Lévi-Strauss - retomando as ideias de Campbell sobre a 'sincronicidade' do mito do herói - foi o investigador em França e a cujos aperfeiçoamentos chamei 'mitocrítica' (1970)" (DURAND, 1979a', p. 36; 2000, p. 187-209).

A mitocrítica inscreve-se na tradição da Nova Crítica, atribuindo um realce privilegiado ao papel e à atuação do mito no interior das narrativas oral ou escrita: "A mitocrítica permite-nos mergulhar o nosso olhar sobre o texto até às últimas confrontações com o gesto dos heróis imemoriais e dos deuses" (DURAND, 2000, p. 198), ou seja, a mitocrítica tem como um dos principais objetivos ler um texto literário na perspectiva mítica: “A mitocrítica estabelece que toda a 'narrativa' (literária certamente, mas também de outras linguagens: musical, cénica, pictural, etc.) entretém um parentesco estreito com o sermo mythicus, o mito" (DURAND, 1996, p. 230). E com o intuito de recuperarmos o gesto e a gesta desses heróis e deuses, porque o mito é sempre politeísta, precisamos observar aquilo que se repete, ou seja, a redundância de algumas imagens “obsessivas” (Mauron, 1983), cuja coerência sincrônica é significativamente pregnante "por detrás das peripécias da narrativa diacrônica" (DURAND, 1996, p. 235).

Para detectar e apropriar-se do mítico nas peripécias da narrativa literária, o mitocrítico, ao longo do exercício hermenêutico da mitocrítica, com os seus conceitos operatórios (DURAND, 1994, p. 38-45, 1996, p. 229-242, 2000, p. 187-209), deve dominar aquilo que Paul Ricoeur (1987, p. 83-99) designa de "dialética de explicação e compreensão" para melhor apropriar-se daquilo que antes lhe escapava. Nesse sentido, o miticiano - é assim que Gilbert Durand (1994, p. 56) designa o hermeneuta dos mitos - deve compreender que a necessidade da dialética da "explicação-compreensão" (RICOEUR, 1986, p. 197-211, p. 161-182, 1987, p. 83-99), que implica sempre uma "análise de conteúdo" (BARDIN, 1991; 
Fundamentos metodológicos do imaginário: mitocrítica e mitanálise

MUCCHIELLI, 2006), deve culminar na interpretação da literatura e da poesia em geral por uma perspectiva mítica.

Os objetivos mais importantes da mitocrítica são:

1) Decifrar, na semântica profunda do texto, os "diversos estratos de sentido na linguagem metafórica e simbólica" (Ricoeur, 1987, p. 89).

2) Interpretar um texto pela redundância de um mitema, que surge sempre num complexo gramatical, num texto graças à "simpatia, intuição, inteligência, compreensão e graça” (Pessoa, s.d., p. 147-148) do leitor.

3) Assinalar os mitos e as suas metamorfoses mais significativas que caracterizam a obra individual de um autor, de uma dada época ou de determinado ambiente psicosociocultural.

De acordo com Durand (1996), o mito decompõe-se em alguns mitemas ou mitologemas indispensáveis que lhe conferem, sincronicamente, o sentido arquetípico, enquanto diacronicamente ele é constituído pelas lições, que podem ser entendidas como leituras ou recepção.

É importante termos em mente o significado dos conceitos de mitema e mitologema. O primeiro foi retomado por Gilbert Durand a partir de Lévi-Strauss (1958, p. 233), que definiu mitema como uma "espessa unidade constitutiva", para designar uma espécie de “átomo" fundamentador do discurso mítico. É a menor unidade do discurso mítico que é redundantemente significativa, isto é, que visa a repetitividade,

uma unidade que não se pode reduzir a uma palavra nem a uma sintaxe e que é constituída por um conjunto semântico, onde, pelo menos, uma palavra é significada, é completada por um atributo, e a posteriori por um verbo. É, portanto, o grupo de palavras que, de algum modo, desempenha o papel mitêmico (DURAND, 1982, p. 85).

Já mitologema foi pescado por Gilbert Durand provavelmente em Jung (1978, p. 353) e corresponde ao "tema" de Raymond Trousson ou à "ideia-força" de Bronislaw Baczko (1984). Ele resulta do empobrecimento do mitema, porque é uma narrativa resumida e abstrata de uma situação mitológica, um esqueleto de uma obra (DURAND, 1983, p. 32). É a "reserva mitológica dos nossos antepassados culturais greco-latinos, que fornecem praticamente todo o arsenal mitológico encontrado em nossa cultura com outros nomes e 
Fundamentos metodológicos do imaginário: mitocrítica e mitanálise

com outros conteúdos culturais, mas cujos esquemas - os mitologemas - são idênticos" (DURAND, 1982, p. 74). O mitologema é, portanto, um tema constituído de unidades menos significativas e menos redundantes do que o mitema. Como exemplo, podemos citar a descida aos infernos, a culpa ou o progressismo prometeico no século XIX.

Estabelecidas as noções de mitema e mitologema, é o momento de compreendermos os passos a serem seguidos para se chegar a eles (DURAND, 1979 $)$ :

1) Relacionam-se os temas, as recorrências simbólicas, que constituem as sincronicidades míticas da obra.

2) Examinam-se as situações e as combinatórias de situações dos personagens e dos elementos que perfazem o plano diacrônico.

3) Utiliza-se um tipo de tratamento à americana, localizando-se as diferentes lições do mito, correlacionado-as com as de outros mitos de uma época ou de um espaço cultural determinado.

É importante destacar que, ao lado da redundância e da diacronicidade que constitui o sermo mythicus, há uma temporalidade cronológica (DURAND, 1979ª) que evidencia as transformações do mito. Além disso, seus mitemas, ou seja "os pontos forte, repetitivos, da narrativa" (DURAND, 1983, p. 29), podem aparecer de forma

1) patente, pela repetição explícita de seus conteúdos homólogos (situações, personagens, emblemas) e

2) latente, pela repetição do seu esquema intencional; nesse caso, os mitemas revestem-se de novas roupagens para cobrir temas antigos. Assim, um mito não se conserva jamais em estado puro, porque há flutuações, ou seja, períodos de inflações e deflações, que garantem a sua sobrevivência (Sanchez Teixeira, 2000, p. 29).

Contemplando a dinâmica do mito, a mitocrítica tem uma elasticidade que permite depreendê-la tanto no nível denotativo quanto conotativo. Dessa forma, a mitocrítica evidencia os mitos diretores e suas transformações significativas. Por meio dela, pode-se acompanhar a trama de relações entre o autor, ou vários autores, e sua incidência na mitologia dominante, processo em que se extrapola o texto para se chegar ao biográfico e ao contexto sociocultural (DURAND, 1979 $)$.

Há uma ligação profunda entre mito, símbolo e vida que se encontra na literatura, de modo que é possível

dissecar a estrutura "mítica" de certos romances modernos, demonstrar a 
Fundamentos metodológicos do imaginário: mitocrítica e mitanálise

sobrevivência literária dos grandes temas e dos personagens mitológicos. (...) a paixão moderna pelos romances trai o desejo de ouvir o maior número possível de "histórias mitológicas" dessacralizadas ou simplesmente camufladas sob formas "profanas" (ELIADE, 1972, p. 163164).

De acordo com Alain Verjat (1989, p. 17-18), a mitocrítica permite operar o mito como procedimento de conhecimento, centrando de maneira centrípeta (e não centrífuga) três polos de leitura (a sociocrítica, a psicocrítica e a crítica textual), uma vez que todos coordenam um relato simbólico, ligam-se à totalidade do mito, que faz com que a estrutura da narração, o meio sócio-histórico e o aparato psíquico, do autor e do leitor, sejam indissociáveis.

Para exemplificarmos, faremos um breve exercício mitocrítico com o poema Eros $e$ Psique, de Fernando Pessoa (1995, p. 93-94), transcrito a seguir:

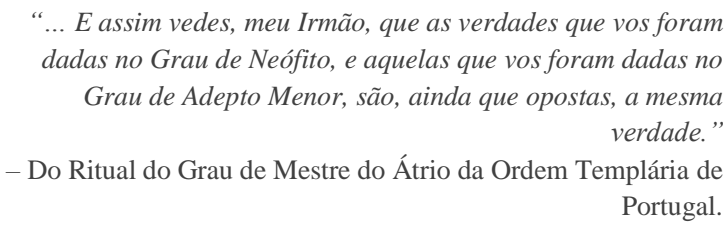

Conta a lenda que dormia

Uma princesa encantada

A quem só despertaria

Um infante, que viria

De além do muro da estrada.

Ele tinha que, tentado,

Vencer o mal e o bem,

Antes que, já libertado,

Deixasse o caminho errado

Por o que à Princesa vem.

A Princesa Adormecida,

Se espera, dormindo espera.

Sonha em morte a sua vida,

E orna-lhe a fronte esquecida,

Verde, uma grinalda de hera.

Longe o Infante, esforçado,

Sem saber que intuito tem,

Rompe o caminho fadado.

Ele dela é ignorado.

Ela para ele é ninguém. 
Fundamentos metodológicos do imaginário: mitocrítica e mitanálise

\author{
Mas cada um cumpre o Destino - \\ Ela dormindo encantada, \\ Ele buscando-a sem tino \\ Pelo processo divino \\ Que faz existir a estrada. \\ E, se bem que seja obscuro \\ Tudo pela estrada fora, \\ E falso, ele vem seguro, \\ $E$, vencendo estrada e muro, \\ Chega onde em sono ela mora. \\ E, inda tonto do que houvera, \\ À cabeça, em maresia, \\ Ergue a mão, e encontra hera, \\ E vê que ele mesmo era \\ A Princesa que dormia.
}

O poema relata um rito de iniciação, mas é também encontro entre Animus e Anima e, em certa medida, propõe um processo de individuação.

Anima é a personificação de todas as tendências psicológicas femininas na psique do homem - os humores e sentimentos instáveis, as intuições proféticas, a receptividade ao irracional, a capacidade de amar, a sensibilidade à natureza $\mathrm{e}$, por fim, mas nem por isso menos importante, $\mathrm{o}$ relacionamento com o inconsciente. (JUNG, 2000, p. 177).

O animus é a personificação masculina do inconsciente na mulher. "Mas o animus não costuma se manifestar sob a forma de fantasias ou inclinações eróticas; aparece mais comumente como uma convicção secreta 'sagrada"' (2000, p. 189).

A lenda, à maneira dos contos de fadas, parece relatar a conhecida história da princesa encantada à espera de seu príncipe. A primeira surpresa nos vem quando descobrimos que o infante percebe que ele e a princesa são um só. Etimologicamente, infante é aquele que não fala; mais do que criança, aqui ele é o que não fala porque não sabe ("Sem saber que intuito tem”). Só saberá quando, depois de trilhar um longo caminho, jornada de todo herói, acordar, já não mais como infante, já não mais como princesa, mas como iniciado.

Os dois - o herói e seu deus último, aquele que busca e aquele que é encontrado - são entendidos, por conseguinte, como a parte externa e interna de um único mistério auto-refletido, mistério idêntico ao do mundo manifesto. A grande façanha do herói supremo é alcançar o conhecimento dessa unidade na multiplicidade e, em seguida, torná-la conhecida 
Fundamentos metodológicos do imaginário: mitocrítica e mitanálise

(CAMPBELL, 1993, p. 43).

Atendo-nos às categorias hermesianas, o poema resgata o mitema da estrada. É ela um processo divino, processo de (auto)conhecimento, de gnose. Uma leitura psicológica, em conformidade com esses elementos que levantamos, assinalaria o encontro do animus com sua anima na tomada de consciência do self, processo de individuação. No campo religioso da mitologia, a afirmação da hierogamia, o casamento sagrado, seria um bom começo interpretativo. É nessa acepção que reencontramos o título, em referência ao longo caminho de provas iniciáticas que Psique teve de percorrer para reconquistar os cuidados de Eros, denunciando ao mesmo tempo a distância e a possibilidade de união entre o humano e o divino.

Aqui é importante atentarmos para o fato de que, na relação entre mito e literatura, a nomeação do mito não é suficiente para que o mito esteja de fato presente. Por outras palavras, não é porque o poema narre o mito de Eros e Psique que efetivamente Eros e Psique sejam os mitos diretores da obra. De fato não o são, pois figuram como símbolos, como mitemas que se referem a outro mito, no caso Hermes.

Os mitemas hermesianos encontrados no poema relacionam o infante à agilidade e ao poder do ínfimo, há também a mediação que a estrada, processo divino, opera no (re)conhecimento. O caráter psicagogo do infante, que acorda sua psique é outro desses mitemas. Portanto, os três mitemas principais de Hermes - o poder do pequeno, o mediador e o guia (psicagogo, iniciador, condutor de almas) -, mitografados por Durand (1979 ${ }^{\mathrm{b}}$, p. 148-150), reincidem de modo obsedante ao longo do poema. Não é difícil ver que o infante que percorre a estrada não é o herói que enfrenta o monstro, mas o andarilho quase distraído, sem intuito e tino, que vence o mal e o bem, para cumprir-se em seu destino iniciático, para operar a união do que caminha e do que espera, do animus e da anima, de Eros e Psique, de quem "sonha em morte a sua vida" com quem busca "sem tino", numa coincidentia oppositorum.

Além disso, o poema reproduz um tema gnóstico, em que o conhecimento é apresentado como despertar:

O "despertar" implica a anamnesis, o reconhecimento da verdadeira identidade da alma, ou seja, o reconhecimento de sua origem celestial. Somente depois de havê-lo despertado é que o "mensageiro revela ao 
Fundamentos metodológicos do imaginário: mitocrítica e mitanálise

homem a promessa da redenção e finalmente lhe ensina como deve comportar-se no Mundo (ELIADE, 1972, p. 115).

Eis como, a partir da análise de um único poema, podemos chegar à revelação de seu substrato mítico. No entanto, aconselha-se, no exercício mitocrítico, o estudo da obra estendida do poeta, bem como do período em que viveu e produziu. Entrementes, não é preciso referenciar toda a obra para perceber como o mito, dinamicamente, a dirige (Almeida, 2011). Da mitocrítica (Brunel, 1992, Gutiérrez, 2012; Vierne, 1981, p. 79-85; Paula Carvalho, 1998, p. 77-182) passamos para o segundo momento da mitodologia durandiana: a mitanálise, mais adequada para detectar os mitos diretores que circulam na chamada Tópica "sociocultural", tal como ela foi concebida por Gilbert Durand (2000, p. 137-162).

\subsection{Mitanálise}

O conceito de mitanálise foi usado, pela primeira vez, por Denis de Rougemont na sua obra Comme Toi-Même. Essais sur les mythes de l'amour. Gilbert Durand retoma-o em 1976 no seu artigo intitulado La Cité et les Divisions du Royaume vers une Sociologie des Profondeurs, e fá-lo novamente aparecer na sua obra Figures Mythiques et Visages de l'Oeuvre, passando por outros estudos (Durand, 1980; 1981; 1982; 1983). Num dos seus últimos trabalhos, intitulado precisamente Introduction à la Mythodologie. Mythes et sociétés (Durand, 2000, p. 83-162), o conceito é amplamente desenvolvido e o seu potencial heurístico é explorado mediante os seus principais conceitos operatórios.

A mitanálise é

um método de análise científica dos mitos que visa extrair não somente o sentido psicológico (Paul Diel, James Hillman, Yves Durand), mas o sentido sociológico (Cl. Lévi-Strauss, D. Zahan, G. Durand). Mitanálise que desde o início alarga o campo individual da psicanálise, na orientação da obra de Jung, ultrapassando a redução simbólica simplificadora de Freud, e repousa sobre a afirmação do 'politeísmo' (M. Weber) das pulsões da psique. A mitanálise sociológica (G. Durand) inspirando-se simultaneamente nos trabalhos do estruturalismo de Cl. Lévi-Strauss, mas igualmente (...) em todas as investigações temáticas ou nas análises semânticas de conteúdos, procura identificar os grandes mitos diretores dos momentos históricos e dos tipos de grupos e de relações sociais (DURAND, 1979ª , p. 313). 
Fundamentos metodológicos do imaginário: mitocrítica e mitanálise

A mitanálise analisa, portanto, a criação artística, mítica, cultural nos diversos contextos histórico-socioculturais onde os vários tipos de criação referidos advêm, visto que na prática não é viável, nem credível, separar uma determinada criação particular do seu contexto sociocultural e vice-versa. Por outras palavras, o que queremos dizer é que um texto ou uma obra artística singular são sempre o resultado do cruzamento da história, dos movimentos sociais, dos tipos psicológicos e das biografias. $\mathrm{O}$ agora afirmado significa que os domínios estudados pela mitocrítica e pela mitanálise se interceptam porquanto o texto analisado pela primeira emerge sempre num contexto que é do domínio de análise da segunda:

a mitanálise pode assim proceder de dois modos: ou ela prolonga naturalmente a mitocrítica, e esta via é preferencialmente seguida pelos literatos formados na análise dos textos, ou - e é a via filosófica - ela parte de sequências e de mitemas de um mito bem estabelecido para ler as ressonâncias de dada sociedade ou de dado momento histórico. Sem nunca perder de vista, todavia, que toda a sociedade é modelada por uma tópica sistémica e que a alma de um grupo (povo, etnia, nação, ou tribo...) é sempre mais ou menos 'malhada' (DURAND, 2000, p. 224-225).

A mitanálise tenta perceber, por um lado, como é que determinada ideologia ou movimento sociocultural moldados por um determinado contexto histórico é tributário, nas suas diversas expressões, de determinadas figuras míticas, de certos mitos diretores, ainda que degradados, e, por outro, procura igualmente perceber como é que esses mitos ou figuras míticas permanecem, derivam ou se desgastam (DURAND, 1996, p. 81-107). A mitanálise visa, portanto, a detecção dos traços míticos, temas míticos, mitos, figuras míticas latentes ou difusas (devedoras dum mito implícito) e patentes (devedoras dum mito explícito). Acontece que nem sempre é possível delimitar os elementos míticos em contextos socioculturais pelo fato desses mesmos elementos se encontrarem "desfigurados", "estilhaçados" no interior das ideologias que modelam ou enformam esses contextos (DURAND, 2000, p. 163-186). Por isso é que Gilbert Durand sempre alertou que a tarefa de identificação e do estudo das dominantes míticas na diversidade das formas da vida social, de um grupo, de toda uma sociedade ou mesmo duma época torna-se, a maioria das vezes, complexa, porquanto levanta problemas de interpretação e de prova hermenêutica. 
Fundamentos metodológicos do imaginário: mitocrítica e mitanálise

Por conseguinte, o "sociólogo das profundidades" não tem a sua tarefa facilitada porque as dominantes míticas nos contextos sócio-históricos encontram-se latentes ainda que certos indícios aflorem à superfície, o que permite ao miticiano, mediante um trabalho laborioso de análise na base das orientações avançadas pelo próprio Gilbert Durand, dar-se conta do perfil mítico em causa. Por outras palavras, a mitanálise tem como uma das suas missões identificar "os núcleos míticos ou simplesmente simbólicos que são significativos de uma sociedade em um dado momento da sua formação" (DURAND, 2000, p. 216-217), além disso o intérprete tem que estar consciente de que a partir da construção de um "mito ideal" dominante é possível estudar as flutuações desse mito através das sequências cronológicas até seu esgotamento final, e, paralelamente, ver como esse mito dominante, atualizado em ideologias e instituições, suscita um contra-mito cujas manifestações são menos manifestas ou patentes.

O miticiano deverá estar atento aos elementos míticos patentes ou latentes quer nos textos propriamente ditos, os educacionais por exemplo, quer nos contextos socioculturais e históricos nos quais eles são produzidos e se encontram. No entanto, essa detecção não se afigura nada simples e isso devido a duas razões:

1) a primeira obriga a que o miticiano tenha um conhecimento sólido dos mecanismos hermenêuticos, possua, no nosso caso, uma ampla e segura visão da tradição mítica ocidental sem, contudo, esquecer as tradições culturais de que essas mesmas mitologias são solidárias e, por último, que possua uma sensibilidade mítico-simbólica, em tudo semelhante à empatia (à Einfühlung) que é necessária aos psicanalistas, que Fernando Pessoa chamaria de "simpatia" e que Karl Kérenyi (1974) designa "ouvido" especial;

2) a segunda razão obriga já o seu "artesão" a conhecer não somente a obra de dado autor ou autores de dada época, bem como a conhecer a "bacia semântica" na qual esse ou esses autores "confeccionaram" os seus produtos culturais - veja-se, por exemplo, o estudo de Patrice Cambronne (1982) que parte de uma mitocrítica das Confissões de Santo Agostinho para terminar em um estudo mitanalítico no qual explica como é que a corrente augustiniana irrigou uma grande parte do cristianismo ocidental.

Por último, a mitanálise, na sua acepção mais ampla, representa um contributo, entre outros possíveis, para estimular um conflito de interpretações que é, a nosso ver, uma das condições para que a hermenêutica não se esgote e que, por consequência, se afaste inelutavelmente do semantismo poderoso veiculado pelas "vidas das imagens" 
Fundamentos metodológicos do imaginário: mitocrítica e mitanálise

(WUNENBURGER, 2002). Por outras palavras, a mitanálise requer a imersão numa espécie de arcaísmo das profundezas de determinada "bacia semântica" para em seguida emergir como "a via possível de uma descoberta, de uma prospecção, de uma profecia" (RICOEUR, 2002, p. 176) doadora de significações simbolicamente pregnantes (Cassirer, 1994).

Para a plena realização da mitanálise, o miticiano deve compreender e utilizar dois conceitos operatórios da mais alta relevância no tratamento dos lugares e tempos, que funcionam como "ferramentas" hermenêuticas: 1) "tópica sociocultural" e 2) "bacia semântica" (DURAND, 2000, p. 211-231).

1) A tópica sociocultural (DURAND, 2000, p. 137-162): o espaço natural das produções políticas, ideológicas e científicas é o do "nível racional" (o "superego" institucional), enquanto o "nível actancial" (o "ego" societal), estando mais próximo do "nível fundador" (o "isso" psicoide), oferece melhores condições para acolher as produções literárias e artísticas, visto que neste nível a pregnância simbólica é ainda elevada, assim como o índice mítico está ainda a racionalizar-se progressivamente. $\mathrm{O}$ que pretendemos pois dizer é que graças à tópica sociocultural (DURAND, 2000, p. 151) pode-se compreender melhor os movimentos míticos quer ascensionais (racionalização progressiva do mítico: máximo de racionalidade - discursos unívocos), que circulam desde o "nível fundador" da tópica até ao "nível racional", passando pelo "nível actancial", quer descensionais (mitologização progressiva dos conteúdos ideo-racionais: máximo de nãoracionalidade - discursos dilemáticos), ou seja, aqueles que partem do "nível racional", passando pelo "nível actancial”, até ao "nível fundador":

Constata-se que se parte de uma extremidade saturada de ribeiros de imagens do 'isso': é amostra confusa de um imaginário que, paulatinamente, se regulariza com os diversos papéis na sua parte mediana, para terminar muito empobrecido na sua extremidade superior, em que o alógico do mito tende a esbater-se em proveito da lógica corrente. É portanto num percurso temporal que os conteúdos imaginários (sonhos, desejos, mitos etc.) de uma sociedade nascem num ribeiro confuso, mas importante, e consolidam-se 'teatralizando-se' (Jean Duvignaud, Michel Maffesoli) nos desempenhos 'actanciais' (Algirdas Greimas, Yves Durand), positivos ou negativos, que recebem as suas estruturas e o seu valor de 'confluências' sociais diversas (apoios políticos, económicos, militares, etc), para finalmente racionalizar-se e logo perder a sua espontaneidade mitogénica nos edifícios filosóficos, nas ideologias e nas codificações (DURAND, 1994, p. 63). 
Fundamentos metodológicos do imaginário: mitocrítica e mitanálise

É pois neste movimento ora ascensional, ora descensional que o miticiano pode caçar, ao nível do manifesto ou do patente, a "presa mítica" ainda que metaforizada.

2) A bacia semântica: o conceito agora tratado inspira-se na metáfora potomológica (do grego potamos: rio) ou hidrográfica (a "bacia fluvial"), e já implícito no conceito de tópica sociocultural, serve para explicar os percursos, as permanências e as mudanças míticas, em determinados momentos da vida de uma sociedade, de um renascimento, ressurgência ou emergência e "adormecimento" de dado mito (DURAND, 1996, p. 81107), mesmo sob a forma de mitologemas, no interior da memória coletiva e sociocultural de determinada sociedade constituída pelos seus modos de vida, herança cultural, língua natural, arquivos históricos etc. Todavia, esta memória social está em constante movimento, pois recebe em permanência novas informações, enquanto outras se perdem ou tenderão mesmo a eclipsar-se, e sofre igualmente a consequência de acontecimentos externos que a afetarão e a moldarão de modo mais ou menos perene: "é assim que se passa de um trend (que significa corrente e cujo começo se faz ainda latentemente, ocultado por "ribeiros") hercúleo, a um outro mercuriano, depois apolínio, prometeico, dionisíaco etc.” (p. 81-107). Por outras palavras, ao fim de uma geração ( 25 a 30 anos) ou de um período de um século, operam-se mudanças significativas, tanto quantitativas com qualitativas, motivadas pela reinjeção, que não é uma repetição mecânica estereotipada, de informação e de acontecimentos sociopolíticos, culturais e econômicos que marcam os estilos duma época. É pois este tipo de re-injeção, que atua no seio de um conjunto sociocultural, que Gilbert Durand denomina de "bacia semântica" a qual pode ser interpretada na base das "estruturas antropológicas do imaginário" tal como Gilbert Durand as concebeu (1984). Por fim, é esta "bacia semântica" que nos ajuda a melhor compreender a dinâmica do imaginário mediante as diversas fases que a constituam ou a caracterizam, a saber: a fase do "escoamento"; a fase da "divisão das águas"; a fase das "confluências"; a fase do "nome do rio"; a fase da “organização dos rios" e, última fase, os "deltas e os meandros" (DURAND, 1994, p. 6976).

Quando se trata de textos fortemente ideologizados há uma noção, a de ideologema ${ }^{4}$, que aparece bem colocada para nos ajudar a melhor compreender a articulação do social e

\footnotetext{
${ }_{4}^{4}$ Trata-se de uma figura dotada de uma forte capacidade heurística forjada por nós sobre o
} conceito de mitologema de Gilbert Durand e que, consequentemente, nada tem a ver, como 
Fundamentos metodológicos do imaginário: mitocrítica e mitanálise

do mítico no interior do imaginário politico, socio-histórico, educacional, entre outros. Assim, Alberto Araújo, na linha dos estudos de Jean-Pierre Sironneau (1980, p. 9-28, 1982, 1993, p. 49-63, p. 215-234), demonstrou que em textos educacionais (ARAÚJO, 1997), e não em ideologias políticas, como Sironneau, os traços míticos encontram-se degradados, disseminados num outro tipo de discurso que, à primeira vista, não revela qualquer semelhança com qualquer mito, figura ou mesmo estrutura mítica. Isso porque no imaginário social (ideologia-utopia), histórico, político, científico e educacional os traços míticos muito raramente se encontram à superfície, o que exige do "miticiano" (a expressão é de Gilbet Durand, 1994, p. 56) um cuidado hermenêutico acrescido em seu tratamento mitodológico. Efetivamente aquilo que aparece nesses textos é, no fundo, uma mistura de ideologia com resquícios míticos (ideologema) que importa recensear mediante a mitodologia durandiana (mitocrítica e mitanálise) tal como foi delineada.

Neste contexto, a noção de ideologema aparece como um conceito operativo auxiliar do "miticiano", que foi forjado na base heurística do conceito durandiano de mitologema (tema mítico), da noção durandiana de "trajecto antropológico" (DURAND, 1984, p. 38) ${ }^{5}$, e na constatação de Jung que vê nos substantivos simbólicos, que são os arquétipos (designados de imagens primordiais em Tipos Psicológicos - Jung, 1991, p. 432-438), “o estado preliminar, a zona matricial da ideia" (JUNG, 1991, p. 435). Durand (1984, p. 6263). Podemos assim definir o ideologema como um complexo significante que articula e mobiliza, ao nível actancial (eu social da "tópica"), o sentido figurado (semantismo simbólico e afetivo-emocional) com as ideias-força veiculadas pelas ideologias (orientações mais conceptualizadas, mais abstratas e rarefeitas) e presentes em dado contexto histórico sociocultural. É, portanto, um conceito que resulta da interação das facetas arquetipal (símbolos primários-mitos) e sociocultural (ideologia-utopia) do Imaginário Bidimensional e condensa, num discurso racionalizante, mediante as metáforas e alegorias, o fluxo de imagens arquetípicas provenientes do nível fundador (o inconsciente coletivo específico com

alguns apressadamente o julgaram, com a noção de ideologema de Mikhail Bakthin e de Julia Kristeva.

${ }^{5} \mathrm{O}$ autor define este conceito crucial da sua obra como "a incessante troca que existe ao nível do imaginário entre as pulsões subjetivas e assimiladoras e as intimações objetivas emanando do meio cósmico e social". Mais adiante diz que o imaginário "não é mais do que este trajeto no qual a representação do objeto se deixa assimilar e modelar pelos imperativos pulsionais do sujeito, e no qual reciprocamente, como magistralmente mostrou Piaget, as representações subjetivas explicam-se 'pelas acomodações anteriores do sujeito' ao meio objetivo". 
Fundamentos metodológicos do imaginário: mitocrítica e mitanálise

a sua pluralidade de arquétipos, as Urbilder como queria Adolf Portmann) (ARAÚJO; SILVA, 2003, p. 353-360). Deste modo, percebe-se melhor que o ideologema condense, pela via da racionalização ideometafórica, as imagens arquetípicas sob forma de símbolos primários (Paul Ricoeur) e de símbolos complexos (mitos) e as figuras ideológicas, metafóricas, alegóricas e utópicas no nível racional da "tópica sociocultural” (DURAND, 2000, p. 137-162 e p. 83-136). Este nível corresponde às atividades racionais e lógicas mediatizadas pelas conceptualizações, codificações jurídicas, ideologias, reflexões pedagógicas (no sentido também social do termo), utopias e epistemologias, etc.: "neste nível, o mythos positiva-se, se assim se pode dizer, em epopeia e logiciza-se em logos" (DURAND, 2000, p. 145). Assim, o ideologema aparece como um espécie de submarino que parte do sentido histórico (literal, próprio), situado no porto racional (super-ego social) da "tópica", em direção ao nível fundador (o designado "id" social ou antropológico), passando pelo nível actancial (ego social), com a tarefa de coletar os traços míticos, através dos diferentes sentidos, alegórico, metafórico e anagógico, a fim de fazer o caminho inverso. Este caminho será sempre um movimento de vaivém contínuo em direção ao nível racional, mas antes procedendo, no nível actancial (theatrum societatis com os seus atores, hierarquias, castas, estratificações), a uma espécie de trabalho de centrifugação através das metáforas e das alegorias em que o sentido verbal e epitético das imagens se substancializa, ou, como diriam Jean Duvignaud e Michel Maffesoli, se teatraliza (DURAND, 2000, p. 140145).

Do exposto, o ideologema é encarado como um conceito heurístico que traz uma espécie de valor acrescentado à mitanálise durandiana. Um tipo de imaginário ideológico, situado entre o espartilho ideológico e a os traços degradados do mito, necessita de um conceito que articule em si essas especificidades e que delas dê conta ainda que sob a influência de metáforas, alegorias, símbolos culturais e de outras figuras de estilo inerentes à linguagem da educação (Reboul, 1984, 1994). Assim, para exemplificarmos, os textos educacionais são um viveiro fértil de metáforas da luz, hortícola, da modelagem, da viagem, da navegação etc., como bem ilustraram Israel Scheffler (1970), Daniel Hameline (1986) e Nanine Charbonnel 1991ª $\left.1991^{\mathrm{b}}, 1993,1997\right)$, para tão-somente mencionar alguns dos autores mais conhecidos. 
Fundamentos metodológicos do imaginário: mitocrítica e mitanálise

\subsection{Mitos contemporâneos}

No caso de Gilbert Durand, há um exercício mitanalítico modelar em Figures Mythiques et Visages de L'oeuvre: de la mythocritique à la mythanalyse, do qual Hermes emerge como mito diretor do início do século XX. Durand (1979ª , p. 243-306) inicia sua análise mostrando como o mito unitário de Prometeu, regente do século XIX, cedeu espaço para a emergência de uma ética do pluralismo, que lentamente começou a ocupar espaço no início do século, primeiramente com os aspectos da perversão, analisados nas obras de André Gide e Herman Hesse, passando por uma segunda etapa, em que o pluralismo ainda não realiza a alteridade (visível, por exemplo, na obra de Marcel Proust), para finalmente encontrar, na obra de Carl Gustav Jung, a plenitude, o reino de Hermes.

O mito de Hermes já não aceita as velhas categorizações herdadas do Iluminismo, rompendo as fronteiras entre a crítica literária e as análises sociocultural e histórica. Já não aceita os valores positivistas, as noções de progresso, mas resgata e valoriza a dimensão da imaginação, que não pratica a redução, buscando, antes, a equivalência de valores entre o mundo do imaginário e o mundo da história e da economia. Nesse sentido, uma obra de ficção não é menos importante que uma de filosofia ou de ciência, já que todas as obras expressam pluralmente o mundo do imaginário, essa constante mediação simbólica que empresta sentido na relação do homem com o mundo, com o outro e consigo mesmo.

De nossa parte, iniciamos o estudo dos mitos contemporâneos, encontrando ao menos quatro grandes mitos norteadores da pós-modernidade tardia, que são Frankenstein, Drácula, Fausto e o mito do fim do mundo (GUIMARÃES et. al., 2016). No caso dos três primeiros, figurados por meio de personagens literárias fundamentais da modernidade, o que os une é a simbolização do desejo de imortalidade e da eterna juventude, o que indica uma reversão da ordem natural. O mito que sustenta essas figuras particulares é Prometeu, com a sua revolta contra os deuses, que se substancializa no poder da ciência e da técnica, as quais vem sofrendo importantes mutações.

Frankenstein, Drácula e Fausto, cada um a seu modo, simbolizam o pulsar profundo dos ídolos do tempo atual mediado pela tecnociência, pela biotecnologia, a exaltação da virtualidade e da cibercultura, o predomínio do instantâneo, o fim das metanarrativas e de 
Fundamentos metodológicos do imaginário: mitocrítica e mitanálise

valores da tradição e sua substituição por novos valores, mais fluidos, efêmeros e instáveis, em permanente mudança e tocado pelo excesso, como o prefixo indica: hiperrelativismo, hiperconsumismo, hiper-hedonismo, hiperindividualismo, hiperprogresso, etc. Ainda que a grande dominante comum dos mitos referidos seja o da sua luta contra a morte e, consequentemente, o prolongamento da vida eterna. Assim, constata-se que os temas da imortalidade e da juventude eterna constituem os seus mitologemas principais.

Tais mitos apontam para a obsessão humana de se representar como o novo deus na terra, como um Prometeu biônico com o poder de determinar o que só era possível aos deuses, como aparece no tema ancestral da fonte da eterna juventude e no mito da idade de ouro. A terra é o novo Éden, um paraíso artificial irrigado pelas expectativas de lazer, felicidade e consumo excessivo. Ao lado desse mito do progresso caminha sua imagem reversa, uma cosmovisão que anuncia o "fim do mundo", em uma estrutura mítica escatológica, cujos sinais se tornam visíveis pelas irreparáveis catástrofes ecológicas, a ameaça terrorista, a sombra das armas nucleares, o pessimismo político, entre outros desencantos que tensionam a expectativa de progresso infindável.

Desse modo, dada a perenidade do mito e sua dinâmica de desgaste, mas também de retorno, é possível compreender como cada época lida com seus temores e suas esperanças, como narra suas angústias e suas alegrias, enfim, como se vale dos mitos para a busca de compreensão da condição humana e de seu reiterado desafio de habitar o mundo e nele conviver, não só com seus iguais, mas sobretudo com as diferenças.

\section{A modos de conclusão}

Como anunciamos na introdução, importa interrogarmo-nos sobre a mais-valia da mitodologia durandiana e naturalmente das suas eventuais limitações. A démarche hermenêutica de Gilbert Durand ainda que privilegiando ativamente a via simbólico-mítica não despreza a doutrina clássica dos quatro sentidos (o sentido histórico ou literal, o sentido alegórico, o sentido moral e o sentido anagógico), na sua função e decisão de compreenderexplicar em ordem a conseguir validar uma melhor interpretação. Privilegia, sim, a via simbólica na qual a figura do ideologema desempenha um papel privilegiado no contexto da interpretação de textos fortemente ideologizados e empobrecidos dos pontos de vista metafórico, mítico e simbólico. 
Fundamentos metodológicos do imaginário: mitocrítica e mitanálise

Esta mitodologia adquire um valor heurístico produtivo se não se ativer, como o faz tendencialmente, numa busca, mediante o ideologema, arqueológica do mítico e do símbolo, como se o mítico e o símbolo se encontrassem no "fundo" do texto estudado, mas que seja também capaz de pensar teleologicamente o sentido desse mesmo material recolhido:

O sentido de um texto não está por detrás do texto, mas à sua frente. Não é algo de oculto, mas algo de descoberto. O que é importante compreender não é a situação inicial do discurso, mas o que aponta para um mundo possível, graças à referência não ostensiva do texto (RICOEUR, 1987, p. 99).

Assim, para pensar teleologicamente o mítico-simbólico impõe-se que este seja objeto de uma interpretação crítica ou de profundidade visando desvelar o seu sentido mais instaurador de um novo modo de ser para o sujeito que interpreta (WUNENBURGER, 2002, p. 91-103). Por isso, pensamos que a interpretação, enquanto dialética de explicaçãocompreensão, torna-se necessária para que todo o esforço da mitocrítica e da mitanálise não seja em vão, ou seja, que não passe de uma simples captação ingênua do sentido do míticosimbólico, que, por conseguinte, comprometa a legitimidade do próprio processo mitodológico. A interpretação é pensada como apropriação da idealidade do próprio texto e enquanto apropriação "torna-se um acontecimento" porque sempre capaz de desvelar, mediante as referências não ostensivas do texto, novos mundos possíveis (o domínio da utopia) e de inaugurar novos modos de ser no mundo.

Face ao exposto, devemos, inspirados por Paul Ricoeur, olhar para o conceito de interpretação, como aquele capaz de pensar o sentido ideologêmico do texto a partir da sua semântica profunda. Graças à interpretação, somos impelidos a olhar as coisas de uma nova forma e, consequentemente, a pensar também de um outro modo. Assim, se pelos ideologemas acedemos, mediante uma "distanciação metodológica" (Paul Ricoeur), ao mítico e ao simbólico, devemos então não somente escutar aquilo que o mito e o símbolo dizem, como, e é um momento fundamental, também interrogar-nos sobre aquilo de que eles falam à semelhança daquilo que Ricoeur diz da compreensão de um texto: "Compreender um texto é seguir o seu movimento do sentido para a referência [não ostensiva]: do que ele diz para aquilo de que fala" (1987, p. 99).

E sobre aquilo que os textos, saturados ideologicamente e carentes do ponto de vista mítico-simbólico dizem, importa compreender o seu dizer ao nível da sua semântica 
Fundamentos metodológicos do imaginário: mitocrítica e mitanálise

profunda que é mediatizada pelos ideologemas que aparecem sempre como uma estranha mistura de traços ideológicos e de traços alegóricos, metafóricos, simbólicos, míticos, etc. Espera-se que desta mediatização resulte não só uma inteligibilidade semântica acrescida de modo a extrair uma mensagem de universalidade de sentido, de omnitemporalidade da significação (Paul Ricoeur), como também essa mesma mensagem contribua para que o horizonte existencial do intérprete torne-se mais enriquecido. Este enriquecimento dá-se num sentido tecido entre a dialética da arqueologia (virada para "ressurgência de significações arcaicas pertencendo à infância da humanidade e do indivíduo" - RICOEUR, 1995, p. 518) e da teleologia (virada para "a emergência de figuras antecipadoras da nossa aventura espiritual” - 1995, p. 518).

Neste contexto, pensamos convictamente que a mitodologia durandiana contribui no plano da hermenêutica simbólica para a captação e a compreensão dos mitos diretores, das figuras míticas passíveis de habitarem os textos literários, poéticos e musicais (mitocrítica) e de também habitarem os textos mais ideologizados, como, por exemplo, os de tipo sociológico, político, científico, pedagógico-educacional, entre outros (mitanálise). Tanto a mitanálise como a mitocrítica dispõem de uma panóplia de conceitos operatórios capazes de fazer sair do seu esconderijo a "presa" mítica sempre situada num algures textual ou discurso e suas práticas: a mitanálise procura descobrir a partir de um sentido aparente ou manifesto, o do discurso ideológico, um sentido escondido ou latente constituído pela substância míticosimbólica desse mesmo discurso enquanto a tarefa da mitocrítica torna-se mais facilitada na medida em que os mitemas, mitologemas, nomes míticos encontram-se mais à superfície, ou seja, inscrevem-se frequentemente no chamado nível denotativo do texto. Ambas se socorrem da chamada "análise do conteúdo" pela sua importância heurística na análise qualitativa (BARDIN, 1991; MUCCHIELLI, 2006).

Se o afirmado colhe, não deixa também de ser pertinente afirmar que a mitodologia de Gilbert Durand deveria completar-se com o contributo decisivo de Paul Ricoeur particularmente em três pontos que passamos agora a destacar: a trilogia "explicaçãocompreensão-interpretação", o par "metáfora-símbolo" e finalmente a espinhosa questão da "prova" ou da "validade" hermenêutica" (1986, 1987, s. d. [1988], 1995; Popper, 1978)6: a primeira permitiria ajudar o intérprete a melhor decifrar um texto do ponto de vista de uma

\footnotetext{
${ }^{6}$ A este respeito, leia-se a nota 14 (Araújo, 1997, p. 68-70).
} 
Fundamentos metodológicos do imaginário: mitocrítica e mitanálise

semântica profunda onde tendencialmente as imagens míticas se encontram; a segunda ajudaria a melhor compreender a relação crucial entre metáfora e símbolo e vice-versa porque é desta relação produtiva que poderemos esperar alcançar, em última instância, o mito; a terceira permite ao intérprete melhor defender-se da arbitrariedade interpretativa, ou seja, protege-o de cair no erro da sob e sobre interpretação que pode, de algum modo, ser sintetizada pelas seguintes máximas: "se a teoria não se adapta ao povo, mate-se o povo, mas salve-se a teoria" e "que a árvore não esconda a floresta e vice-versa". Por fim, exige-se da parte do hermeneuta durandiano um conhecimento interdisciplinar, o que não é algo dado, de várias disciplinas, como por exemplo História da Mitologia e do Simbolismo, Hermenêutica simbólica e textual, História das Religiões, e domínio competente da sua disciplina específica cujos exemplos bem poderiam ser os seguintes: Ciências da Literatura, Ciências da Educação, Ciências Exatas, Ciências Biológicas, Ciências Religiosas, Ciências Sociais, etc...

Finalmente, recordamos ao leitor que o objetivo do nosso estudo visava explicitar a mitodologia durandiana como fundamento metodológico dos Estudos do Imaginário: a mitanálise, na sua acepção mais ampla, prolonga naturalmente a mitocrítica (vocacionada para os textos literários), que visa a detecção de mitologemas, de traços míticos, de mitos, de alegorias, de emblemas (DURAND, 1979, p. 9-22), de metáforas vivas e de ideologemas nos textos educacionais, históricos, políticos, entre outros, preocupando-se especialmente em estudar a atuação das correntes mitogénicas (leia-se mitos diretores muitas vezes em tensão numa determinada época cultural) que irrigam os contextos socioculturais. Por conseguinte, decorre do afirmado que na nossa prática hermenêutica privilegiamos especialmente a mitanálise compreendida no seu sentido mais amplo. No nosso terceiro ponto procuramos ilustrar, na base dos mitos contemporâneos, os procedimentos metodológicos por nós desenvolvidos nos pontos anteriores.

\section{Referências}

ALMEIDA, Rogério de. O Criador de Mitos: educação e imaginário em Fernando Pessoa. São Paulo: Educ, 2011. 
ARAÚJO, Alberto Filipe \& SILVA, Armando Malheiro da. "Mitanálise: Uma Mitodologia do Imaginário?". In: ARAÚJO, Alberto Filipe \& BAPTISTA, Fernando Paulo (Coord.). Variações Sobre O Imaginário. Domínios, Teorizações, Práticas Hermenêuticas. Lisboa: Instituto Piaget; 2003, p. 339-364.

O "homem novo" no discurso pedagógico de João de Barro. Ensaio de mitanálise e de mitocrítica em educação. Braga: IEP/CIED/UM, 1997.

BACZKO, Bronislaw. Les Imaginaires Sociaux. Mémoires et Espoirs. Paris: Payot, 1984. BARDIN, Laurence. Análise de conteúdo. Trad. de Luís Anrero Augusto. Lisboa: Edições 70.

BRUNEL, Pierre. Mythocritique. Théorie et Parcours. Paris: PUF, 1992.

CAMBRONNE, Patrice. Recherches sur les structures de l'imaginaire dans les Confessions de Saint Augustin. Paris: Études Augustiniennes, 1982.

CAMPBELL, Joseph. O Herói de Mil Faces. São Paulo: Cultrix / Pensamento, 1993.

CHARBONNEL, Nanine. La Tâche aveugle. Vol. 1 - Les aventures de la métaphore; Vol. 2 - L'important c'est d'être propre; Vol. 3 - Philosophie du modèle. Strasbourg: Presses Universitaires de Strasbourg, 1991a, 1991b, 1993.

La métaphore de la lumière dans le discours sur l'éducation. Revista

Portuguesa de Educação, vol. 10, n $2,59-70$.

DURAND, Gilbert. A Imaginação Simbólica. Trad. de Maria de Fátima Morna. Lisboa: Arcádia, 1979.

Figures Mythiques et Visages de L'œuvre. Paris: Berg International, 1979a.

. Science de l'homme et tradition. Paris: Berg International, 1979b.

. L'Imaginaire. Essai sur les sciences et la philosophie de l'image. Paris:

Hatier, 1994.

. Champs de l'Imaginaire. Textes réunis para Danièle Chauvin. Grenoble: Ellug, 1996.

Introduction à la Mythodologie. Mythes et Sociétés. Paris: Albin Michel, 2000.

Les Structures Anthropologiques de l'Imaginaire. 10̀̀ ed.. Paris:

Dunod, 1984. 
Mito e Sociedade. A Mitanálise e a Sociologia das Profundezas. Trad. de Nuno Júdice. Lisboa: A Regra do Jogo, 1983.

Mito, Símbolo e Mitodologia. Trad. de Hélder Godinho e de Vitor

Jabouille. Lisboa: Presença, 1982.

ELIADE, Mircea. Mito e Realidade. São Paulo: Perspectiva, 1972.

GUIMARÃES, A. R.; ARAÚJO, A. F.; RIBEIRO, J. A.; ALMEIDA, R. Olhares sobre Frankenstein: literatura, educação e cinema. 2a edição. Coleção Mitos da PósModernidade - Vol. 1. São Paulo: Képos, 2016.

GUTIÉRREZ, Fátima. Mitocrítica. Naturaleza, función, teoría y práctica. Lleida: Editorial Milenio, 2012.

Les Racines de la Conscience. Étude sur l'archétype. Trad. d'Yves Le Lay. Paris: Buchet/Chastel, 1978.

Types Psychologiques. Trad. d'Yves le Lay. Paris/Genève: Georg Éditeur, 1991.

et al. O Homem e seus Símbolos. Rio de Janeiro: Nova Fronteira, 2000.

HAMELINE, Daniel. L'éducation, ses images et son propos. Paris: ESF, 1986.

KERÉNYI, Karl. "De l'Origine et du Fondement de la Mythologie". In JUNG, Carl Gustav \& KERÉNYI, Charles. Introduction à l'Essence de la Mythologie. Trad. par H. E. Del Medico. Paris: Payot, 1974, p. 11-41.

LÉVI-STRAUSS, Claude. Anthropologie Structurale. Paris: Plon, 1958.

MAURON, Charles. Des Métaphores Obsédantes au Mythe Personnel. Introduction à la Psychocritique. Paris : Librairie José Corti, 1983.

MUCCHIELLI, Roger. L'analyse de contenu : des documents et des communications. $9^{\mathrm{e}}$ éd. Issy-les-Moulineaux : ESF.

PAULA CARVALHO, José Carlos de. Imaginário e Mitodologia: Hermenêutica dos Símbolos e Estórias da Vida. Londrina: editora URL, 1998.

PESSOA, Fernando. Mensagem e Outros Poemas Afins seguidos de Fernando Pessoa e a ideia de Portugal. $2^{\mathrm{a}}$ ed. Mem Martins: Europa América, s/d.

Poemas de Fernando Pessoa. Lisboa: Europa-América, 1995.

POPPER, Karl. La Logique de la Découverte Scientifique. Trad. de Nicole Tyssen-Rutten e Philippe Devaux. Paris : Payot. 


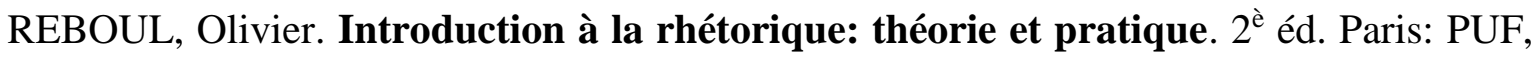
1994.

Le langage de l'éducation. Paris: PUF, 1984.

RICCEUR, Paul. Du texte à l'action. Essais d'herméneutique, II. Paris: Du Seuil, 1986.

Teoria da Interpretação. Trad. de Artur Morão. Porto : Porto Editora, 1987.

O conflito das interpretações: ensaios de hermenêutica. Trad. de M.

F. Sá Correia. Porto: Rés, s. d. [1988].

De l'interprétation. Essai sur Freud. Paris : Du Seuil, 1995.

. Philosophie de la Volonté. II. Finitude et Culpabilité. Paris: Aubier,

2002.

ROUGEMOnT, Denis. Comme Toi-Même. Essais sur les Mythes de l'Amour. Paris :

Albin Michel, 1961

SANCHEZ TEIXEIRA, Maria Cecília. Discurso pedagógico, mito e ideologia: o imaginário de Paulo Freire e de Anísio Teixeira. Rio de Janeiro: Quartet, 2000.

SIRONNEAU, Jean-Pierre. Retour du mythe et imaginaire socio-politique. In : AA.VV. Le Retour du Mythe. Grenoble : PUG, 1980, p. 9-28.

. Sécularisation et religions politiques. Paris : Mouton, 1982.

. Figures de L'Imaginaire Religieux et Dérive Idéologique. Paris:

L'Harmattan.

SCHEFFLER, Israel. El lenguaje de la educación. Trad. de Marcelo Pérez Rivas. Buenos Aires: Editorial "El Ateneo", 1970.

VERJAT, Alain y otros. El retorno de Hermes. Hermeneutica y Ciencias Humanas. Barcelona : Anthropos, 1989.

VIERNE, S. "Pour l'Élaboration d'une Mythocritique". In GRASSIN, Jean-Marie (Coord.). Mythes, Images, Représentations. Actes du XIVe congrès (Limoges, 1977) de la Société Française de Littérature Générale et Comparée. Limoges. Didier, $n^{\circ}$ 79: Trames, Université de Limoges, p. 79-85, 1981.

WUNENBURGER, Jean-Jacques. La Vie des Images. Grenoble: PUG, 2002.

Artigo recebido em: 02/08/2018

Artigo aceito para publicação em: 01/10/2018 